\title{
Pollen-mediated gene flow across fragmented clonal stands of hybrid eucalypts in an exotic environment
}

\author{
Paulo H.M. da Silva ${ }^{\mathrm{a}, *}$, Alexandre M. Sebbenn ${ }^{\mathrm{b}, \mathrm{c}}$, Dario Grattapaglia ${ }^{\mathrm{d}, \mathrm{e}}$ \\ a Instituto de Pesquisas e Estudos Florestais (IPEF), Avenida Pádua Dias 11, Caixa Postal 530, CEP 13400-970 Piracicaba, SP, Brazil \\ ${ }^{\mathrm{b}}$ Instituto Florestal de São Paulo, CP 1322, São Paulo, SP 01059-970, Brazil \\ ${ }^{\mathrm{c}}$ Faculdade de Engenharia de Ilha Solteira/UNESP, Caixa Postal 31, Ilha Solteira, SP 15385-000, Brazil \\ d Plant Genetics Laboratory, EMBRAPA Genetic Resources and Biotechnology, CEP 70770-970 Brasilia, DF, Brazil \\ ${ }^{\mathrm{e}}$ Graduate Program in Genomic Sciences Biotechnology and Universidade Católica de Brasília, SGAN Qd 916, CEP 70790-160 Brasília, DF, Brazil
}

\section{A R T I C L E I N F O}

\section{Article history:}

Received 15 July 2014

Received in revised form 2 December 2014

Accepted 4 December 2014

Available online 26 December 2014

\section{Keywords:}

Pollen flow

Paternity analysis

Outcrossing rate

Transgenic tree

Eucalyptus

\begin{abstract}
A B S T R A C T
We investigated the rate of pollen-mediated flow and realized reproductive success at increasing distances from the source, across fragmented clonal stands of hybrid eucalypts in Brazil by parentage analysis of grown out seedlings using genetic data at 15 microsatellite markers. Two study areas were employed: a pollen donor area composed of a clonal stand of a single pollen donor clone (PD) and a pollen sink (PS) area composed of a mixed clonal stand of two other clones (PS1 and PS2). In the pollen sink area four plots with 30 trees each, located at 25, 200, 400 and $550 \mathrm{~m}$ from the PD were established as sink islands. Before flowering, the entire clonal stands of clones PS1 and PS2, with exception of the sink islands were clear cut. Seeds were harvested from five randomly sampled trees in each sink island and the paternity of 15 seedlings per tree, 75 seedlings per island totaling a sample of 300 seedlings, was determined with PD as the alleged father. The self-pollination rate in the sink islands varied from zero to $24 \%$. Paternity assignment to the PD was highest in the island at $25 \mathrm{~m}$ (17.3\%) and rapidly decreased to $4.0 \%$ at $200 \mathrm{~m}$ and $2.7 \%$ at $550 \mathrm{~m}$, suggesting a pattern of isolation by distance, while revealing a large pollen contribution from unaccounted sources across all islands. Our results in a fragmented clonal site agree with previous estimates of general pollen movement in eucalypt seed orchards, showing that pollination will take place by and large at relatively short distances of less than $200 \mathrm{~m}$, consistent with the expected range of flight of pollinator bees. Nevertheless the exponential distribution observed also indicates that low levels of pollination success are to be expected over longer distances. Our data provide useful guidelines regarding the distance at which seed orchards should be established away from potentially large pollen pressure of clonal stands to minimize unwanted pollen introgression. Furthermore, our results on dispersal rate and distance of pollen have direct implications on gene containment strategies and modeling studies, as pollen-mediated gene flow is one of the key determinants of the potential ecological and biosafety impacts of prospective transgenic eucalypts.
\end{abstract}

(c) 2014 Elsevier B.V. All rights reserved.

\section{Introduction}

Understanding the patterns of pollen movement from planted eucalypt forests stands has important implications for nearby breeding operations and for considering the deployment of genetically modified (GM) eucalypts. Pollen dispersal data is vital to determine the distance at which seed orchards should be established away from commercial stands, germplasm banks or unimproved forests, so as to avoid undesired pollen contamination and its resulting negative impact on the genetic quality of the seed

\footnotetext{
* Corresponding author. Tel.: +55 1921058600.

E-mail address: paulohenrique@ipef.br (P.H.M. da Silva).
}

crops. Furthermore, by quantifying the distance of pollen flow from clonal stands, one may provide guidelines to contain or minimize gene flow from prospective transgenic eucalypts stands.

Although studies have assessed the potential seed-mediated gene flow from planted eucalypts into native forests in Australia (Barbour et al., 2010; Larcombe et al., 2013), US (Booth, 2012; Callaham, 2013) and Brazil (da Silva et al., 2011), little information exists regarding pollen-mediated gene flow across eucalypt stands in exotic conditions. Eucalypts are known to be pollinated by insect, birds and bats (Hingston et al., 2004; Southerton et al., 2004). In exotic conditions in Brazil, however, pollination is carried out largely if not exclusively by honey bees (Apis mellifera) which collect pollen from multiple trees and are expected to disperse it 
at relatively short distances due to their limited flight range. Bee cages are ubiquitous in eucalypt forest plantations supporting an important honey industry (Leite et al., 2000). Pollen dispersal studies in Eucalyptus saligna plantations in Brazil using radioactive labeled pollen, revealed effective bee movement up to $100 \mathrm{~m}$ from their hives, with gradually decreasing activity up to a $300 \mathrm{~m}$ distance (Pacheco et al., 1986).

Pollen flow in eucalypts can be efficiently investigated using polymorphic co-dominant genetic markers that allow precise tracking of the paternal genetic contribution by analyzing marker allele inheritance to seedling offspring. The availability of well validated sets of microsatellites have made them the preferred working tool for this purpose in parentage studies in seed orchards (Chaix et al., 2003; Chaix et al., 2007; Chaix et al., 2010; Grosser et al., 2010), notwithstanding issues related to the occurrence of null alleles which need to be adequately addressed to avoid erroneous parentage assignments (Grattapaglia et al., 2004). Such parentage studies have shown complex and variable patterns of pollen dispersal within seed orchards depending on the genetic origin of the individuals involved, flowering synchrony and abundance, and overall ecological conditions. Invariably however, considerable proportions (29-46\%) of pollen contamination of seed orchard crops from external sources have been reported, indicating that trees several hundred meters away from the orchard may ultimately contribute to seed production. Nevertheless no experiment to date specifically aimed at estimating the maximum distance of pollen flow in exotic environments, although an estimate of pollen flow distance of $1.94 \mathrm{~km}$ was reported for Eucalyptus loxophleba in natural stands in Australia (Sampson and Byrne, 2008).

The aim of this study was to carry out a systematic assessment of the rate of pollen flow and realized reproductive success at increasing distances between clonal stands of Eucalyptus urophylla $\times$ Eucalyptus grandis hybrids in tropical conditions in Brazil. Most industrially oriented breeding programs in Brazil make extensive use of outdoor controlled pollination orchards where elite trees are recombined to produce progeny on which selection is advanced. Although clonal deployment is generally preferred, open pollinated seed orchards are still used to provide high quality seeds for plantation in new areas where no clonal recommendation is yet available (Rezende et al., 2014). Furthermore, given the prospects of the impending deployment of transgenic eucalypts (Ledford, 2014) and the current standards of forest certification agencies that still do not allow commercial use of transgenic trees in certified areas, data about the rate of pollen flow across clonal stands is an indispensable information. We used a large set of well validated microsatellite markers and a maximumlikelihood framework for paternity analysis of seedlings to specifically try to answer the following questions: (1) What is the rate of pollen flow and realized reproductive success from a single pollen donor, assessed by genotyping grown out seedlings derived from seeds harvested in fragmented clonal stands of eucalypts? and (2) How does this rate of pollination success changes over increasing distances from the pollen donor source?

\section{Material and methods}

\subsection{Study site and sampling design}

The experimental area was established in a commercial clonal stand of $E$. urophylla $\times E$. grandis hybrids, the most widely planted eucalypts in the tropics, at harvest age ( $6 \mathrm{yr})$. The experiment was located near Itapetininga city, Sao Paulo State, Brazil (2335S, $48^{\circ} 03^{\prime} \mathrm{W}$; and altitude of $670 \mathrm{~m}$ ). To simulate a mainland to islands model of gene dispersion, we selected a clonal stand planted with a single clone, to function as pollen donor (PD) and represent the mainland (Fig. 1). A nearby mixed clonal stand established with two different clones was selected as pollen sink area with two clones (PS1 and PS2) representing the islands. Four islands were established at increasing distances $(25,200,400$ and $550 \mathrm{~m})$ from the pollen donor clonal stand (Fig. 1). The $550 \mathrm{~m}$ distance was the maximum distance available at harvest age that would allow the experiment to be carried out. Although the experimental site was surrounded by commercial stands, we are assured that the specific clone used as pollen donor was not present in neighboring stands as well as in the four islands. In each island a square plot of 30 trees was sampled $\left(6 \times 5\right.$ trees $\left.=180 \mathrm{~m}^{2}\right)$. Before flowering, the entire clonal stand of clones PS1 and PS2, with exception of the 30 tree square plots of the islands were clear-cut. After flowering and fruiting, open-pollinated seeds were collected from a sample of five randomly samples trees in each sink island, each tree therefore constituting a replicate. The number of trees of clones PS1 and PS2 varied across the islands (Fig. 1).

Seeds were geminated and grown at the nursery of the Instituto de Pesquisa e Estudos Florestais (IPEF). No difference was observed among the seedlings from different mother trees in terms of germination, morphology and initial survival. Fifteen randomly selected seedlings per replicate tree, 75 per island and 300 seedlings in total, were sampled at four weeks of age for the parentage study. Leaves from one PD tree and bark of all 20 clonal trees of PS1 and PS2 and leaves of the 300 seedlings were collected and subsequently used for DNA extraction, identity and parentage analysis.

\subsection{DNA extraction and microsatellite genotyping}

DNA was extracted from $\sim 100 \mathrm{mg}$ of fresh or cold air-dried leaf tissue using the extraction procedure optimized earlier for eucalypts (Grattapaglia and Sederoff, 1994). The three clones and the 300 seedlings samples were genotyped at 15 microsatellite markers (EMBRA2, EMBRA28, EMBRA3, EMBRA11, EMBRA10, EMBRA63, EMBRA157, EMBRA204, EMBRA219, EMBRA333, EMBRA128, EMBRA38, EMBRA210, EMBRA12 and EMBRA681), using PCR protocols and fluorescence-based multiplexed detection methods in an automatic genetic analyzer ABI3100XL as described earlier (Faria et al., 2010).

\subsection{Diversity and parentage analysis}

An initial assessment of the overall intensity of gene flow was carried out by looking at the basic genetic diversity measures in the sampled seedlings, both for each island individually as well as for all islands together. The following parameters were estimated: total number of alleles $(k)$, number of private alleles $\left(P_{a}\right)$, average number of alleles per locus $(A)$, observed heterozygosity $\left(H_{o}\right)$ and expected heterozygosity $\left(H_{e}\right)$. The level of inbreeding was estimated using the fixation index $(F)$ and the significance of the $F$ values tested using 1000 Monte Carlo permutations of the alleles among individuals and a sequential Bonferroni correction for multiple comparisons (95\%, $\alpha=0.05$ ). All these analyses were carried out using Fstat (Goudet, 1995). Genetic relatedness among the three parental clones (PD, PS1 and PS2), was estimated by a pairwise kinship coefficient, using the Nason method (Loiselle et al., 1995), and implemented in Spagedi 1.3 (Hardy and Vekemans, 2002).

Paternity analysis was carried out under a maximum likelihood framework implemented in CERVUS 3.0 (Marshall et al., 1998), including the correction to accommodate genotyping inconsistencies (Kalinowski et al., 2007). To provide the critical LOD score values and the Delta $(\Delta)$ statistics (defined as the difference in LOD scores between the most likely candidate parent and the second most likely candidate parent) above which parentage would be assigned with a 95\% confidence level, simulations were carried 

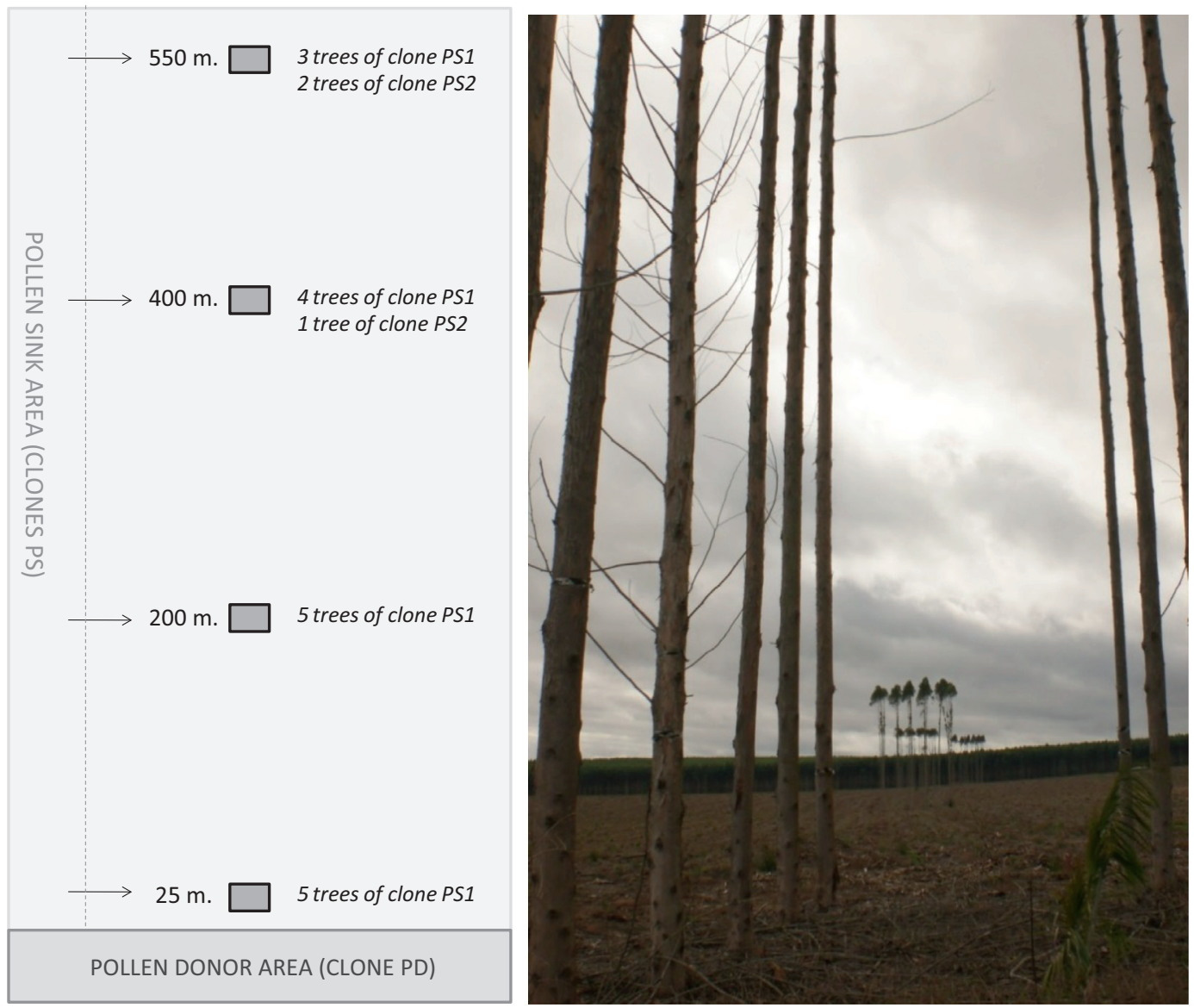

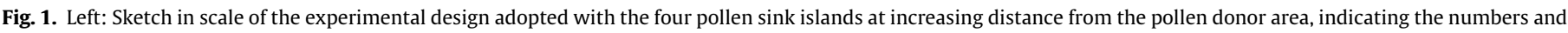

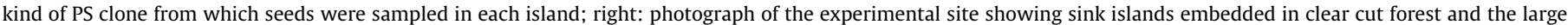
clonal stand acting as pollen donor area in the background.

out using the genotyping data gathered for the three parents and all 300 seedling offspring. Simulations involved one million parent-offspring pairs for maternity determination, and one million trios (mother-father-offspring) for parent-pair determination using the specific routine in CERVUS 3.0. Parameters used in the simulation were as follows: (i) a $5 \%$ genotyping inconsistency, thus allowing for the declaration of parentage even in the presence of occasional parent-offspring genotype mismatches due to mutation or microsatellite allele mistyping; (ii) a proportion of $30 \%$ sampled parents, to account for the possibility of large proportions of foreign pollen contribution. For each seedling, maternity verification was carried out first, followed by the simultaneous verification of paternity and maternity using the parent-pair command. The minimum number of microsatellites used to determine parentage was fixed at 12. If paternity was not assigned to the PD it was considered as having being sired by a pollen source located outside the experimental setting. The selfing rate $(s)$ was estimated as the proportion of seedlings whose full parentage was assigned to the maternal clone only (i.e. the maternal clone acted mother and father), relative to the total number of sampled seedlings. The pollen flow rate from the pollen donor clone (PD) was estimated as the proportion of seedlings whose paternity was assigned to the pollen donor (PD) relative to the total number of outcrossed seedlings.

\section{Results}

The combined power of parent-pair exclusion, i.e. the probability with which the 15 markers adopted would identify non-parents of the sampled seedlings, was high (0.999996), indicating that parentage could be assigned with very high confidence. Furthermore, the estimated kinship coefficients between PD and PS1, PD and PS2 and PS1 and PS2 were respectively $-0.082,-0.072$ and -0.067 , in other words, equal to zero. Such negative values are possible given the estimation method and simply indicate that the three clones are slightly less related than randomly sampled individuals from the theoretical population to which they belong (Hardy and Vekemans, 2002). The correct identity of the 20 mother trees in the four islands from which seedlings were sampled was confirmed based on their genotype data prior to the paternity analysis. The total number of alleles observed at the 15 typed loci in the three parents used in the study (PD, PS1 and PS2) was 55. On the other hand a total of 106 different alleles were observed at the 15 markers when all 300 seedlings together were considered, revealing a high rate of external pollen contribution into the islands from trees not sampled in the study.

When accounted by island, the total number of alleles observed in the seedlings $(k)$, the number of private alleles, i.e. alleles only observed in the seedlings $\left(P_{s}\right)$ and the number of private alleles in seedlings sampled from different islands $\left(P_{i}\right)$ were slightly higher in the two islands farther away from the commercial stands (200 and $400 \mathrm{~m}$ ) but these differences were not significant for any of the parameters when the variation observed across the 15 seedlings of each one of the five mother tree replicates was accounted for (Table 1).

Furthermore, the average number of alleles per locus $(A)$, observed $\left(H_{o}\right)$ and expected heterozygosity $\left(H_{e}\right)$ were similar in the four islands suggesting that the overall pollen contribution 
Table 1

Summary of genetic diversity and pollination success rate from the pollen donor clone (PD) into four pollen sink islands of Eucalyptus urophylla $\times$ E. grandis clones.

\begin{tabular}{|c|c|c|c|c|}
\hline Parameter & $25 \mathrm{~m}$ & $200 \mathrm{~m}$ & $400 \mathrm{~m}$ & $550 \mathrm{~m}$ \\
\hline \# of alleles in the seedlings: $k$ & 82 & 90 & 90 & 82 \\
\hline \# of private alleles in the seedlings: $P_{s}$ & 27 & 35 & 35 & 30 \\
\hline \# uniquely private alleles per island: $P_{i}$ & 3 & 6 & 4 & 3 \\
\hline Average number of alleles: $A$ & $5.5 \pm 1.5$ & $6.0 \pm 2.1$ & $6.0 \pm 1.9$ & $5.5 \pm 2.0$ \\
\hline Observed heterozygosity: $H_{o}$ & $0.73 \pm 0.13$ & $0.70 \pm 0.11$ & $0.74 \pm 0.10$ & $0.72 \pm 0.09$ \\
\hline Expected heterozygosity: $H_{e}$ & $0.63 \pm 0.07$ & $0.61 \pm 0.09$ & $0.64 \pm 0.06$ & $0.68 \pm 0.07$ \\
\hline Fixation index: $F$ & $-0.17 \pm 0.16^{*}$ & $-0.15 \pm 0.12^{*}$ & $-0.16 \pm 0.16^{*}$ & $-0.07 \pm 0.12$ \\
\hline \# of seedlings assayed & 75 & 75 & 75 & 75 \\
\hline \# of seedlings from selfing & 4 & 18 & 5 & 0 \\
\hline Self-pollination rate (\%) & 5.3 & 24.0 & 6.7 & 0.0 \\
\hline \# of seedlings from outcross & 71 & 57 & 70 & 75 \\
\hline Outcrossing rate $(\%)$ & 94.7 & 76.0 & 93.3 & 100.0 \\
\hline \# of seedlings sired by PD & 13 & 3 & 1 & 2 \\
\hline Proportion of seedlings sired by PD (\%) & 17.3 & 4.0 & 1.3 & 2.7 \\
\hline
\end{tabular}

$P<0.05$.

was relatively homogeneous across the islands. The fixation index $(F)$ was negative in all four islands and significantly less than zero in three of them (islands at 25, 200 and $400 \mathrm{~m}$ ), indicating an excess of heterozygous seedlings possibly resulting from selection against more homozygous individuals (Table 1 ). The parentage analysis revealed a variable average selfing rate ranging from 0 to $24 \%$ across the different islands. The total number of seedlings sired by the PD varied significantly from the closer island to the other three, with 13 of the 75 seedlings sired by PD in the island at $25 \mathrm{~m}$, rapidly decreasing to only a few seedlings in the other islands. These numbers translated to estimated rates of pollen flow from PD of $17.3 \%$, decreasing to $2.7 \%$ in the island at $550 \mathrm{~m}$ (Table 1 and Fig. 2). The coefficient of determination $\left(R^{2}\right)$ for the inverse exponential curve that captured the rapid decrease of pollen flow with distance was high (0.87) and significant $(p<0.001)$, indicating that the pollen contribution from the donor area to the islands is strongly determined by distance.

\section{Discussion}

Differently from previous studies that aimed at estimating the overall rate of outcrossing versus selfing, or individual parentage inside seed orchards usually from seed progeny arrays, our study specifically focused on looking the distance and reproductive success of pollen movement across fragmented clonal stands by genotyping established seedlings. In such a setting we aimed at monitoring the potential of a single pollen source to move across increasing distances, reach islands of pollen sink and outcompete external pollen in the actual production of offspring. Average

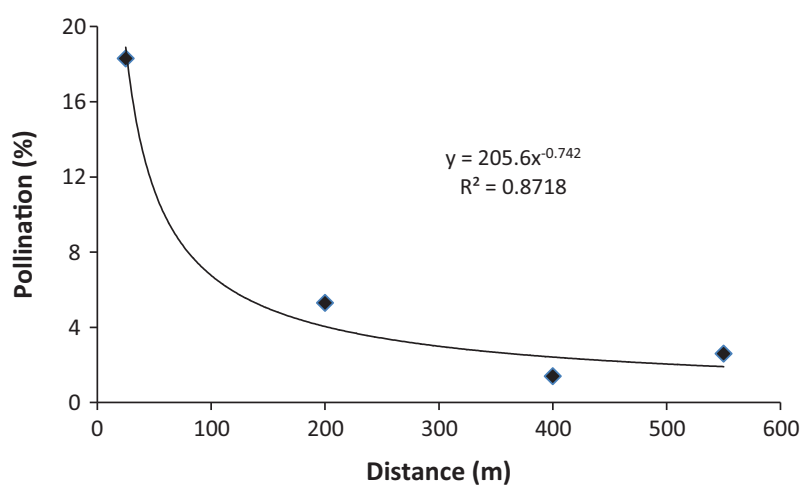

Fig. 2. Pattern of eucalypt pollen dispersal and realized reproductive success as a function of distance between a single pollen donor clone and two pollen sink clones. selfing rates in each island varied from zero to $24 \%$, i.e. outcrossing rates from $100 \%$ down to $76 \%$ (Table 1 ). These estimates are in line with previous estimates of outcrossing rates obtained in E. grandis seed orchards, reported at $86 \%$ to $97 \%$ (Chaix et al., 2003; Jones et al., 2008) and between $89 \%$ and $93 \%$ for E. urophylla (Gaiotto et al., 1997), confirming the preferentially outcrossed mating system of these Eucalyptus species. Interestingly, however, with a slight increase in the island at $200 \mathrm{~m}$ possibly due to random variation, no substantial difference was seen in selfing rates in these clonal stands when compared to the estimates reported in other seed orchards studies (Chaix et al., 2003; Grattapaglia et al., 2004). Opportunity for self-pollination in clonal stands would be expected to be higher than in seed orchards. In clonal stands, selfing would result from actual self-pollination plus the potential cross pollination between nearby trees of the same genotype, as opposed to the pattern expected in seed orchards where several different genotypes are present and opportunity of selfing would only take place by regular self-pollination. This result may be explained by the fact that tree flowering in intensively managed close spaced trees in clonal stands is known to be far less abundant than in seed orchard trees (G.D. Rezende, pers. comm.). This fact, in turn, reduces the abundance of pollen availability and limits the opportunity of extended flowering periods that could overcome the selfing avoidance system of protandry in eucalypts. This result agrees with the largely unsuccessful attempts of eucalypt breeders in Brazil in trying to derive large selfed progenies of elite clones by simply collecting seeds in central areas of large clonal stands and checking them by microsatellite analysis (D. Grattapaglia, pers. comm.). Furthermore, offspring derived from selfing or related matings in eucalypts typically display a considerable inbreeding depression already at the seed stage during fruit development or later when germinating seedlings in the nursery (Griffin et al., 1988; Hardner and Potts, 1995). In fact, we observed a negative and significant excess of heterozygous seedlings in three of the four islands (Table 1), suggesting that unintended selection against more homozygous individuals might have taken place. It is therefore likely that additional selfed offspring that might have been produced, never germinated or resulting weak seedlings were not sampled for genetic analysis.

Pollination success of the pollen donor clone was detected at all four distances sampled. As expected, it was highest at close distance of $25 \mathrm{~m}$ (17.3\%), reducing substantially with increasing distances $(2.7 \%$ at $550 \mathrm{~m})$, suggesting a pattern of isolation by distance following an inverse exponential distribution where most dispersal occurs at short distances with a long tail of low level pollen dispersal over larger distances on course to zero (Fig. 2). These results are generally in line with previous studies in 
eucalypts, despite the wide variation in target species, environmental and management conditions and detection methods, showing that pollen dispersal may have a significant genetic impact up to 200 to $300 \mathrm{~m}$ from the pollen source and less so but still present beyond such distances. Barbour et al. (2005) using morphological markers in a very large set of 119,000 seedlings assayed, found an average pollen migration rate of $7.2 \%$ at $100 \mathrm{~m}$ from commercial Eucalyptus nitens stands into native populations of Eucalyptus ovata, reducing to $0.7 \%$ at 200 to $300 \mathrm{~m}$ and continued at this level for long distances. Burczyk et al. (2002) reported approximately $50 \%$ of pollen coming from distances $40 \mathrm{~m}$ away from the mother tress sampled. Paternity tests in seedlings from a hybrid $E$. grandis $\times E$. urophylla seed orchard revealed that approximately $29 \%$ of the seedlings were sired by external pollen sources expected to be beyond the $300 \mathrm{~m}$ native forest isolation belt that surrounded the seed orchard (Grattapaglia et al., 2004). In an $E$. grandis seed production area, pollination of mother trees was found preferentially outcrossed, although largely not by nearest neighbors, with more than $92 \%$ of pollen coming from trees located at more than $10 \mathrm{~m}$ (Jones et al., 2008). In this same study, an average pollination distance of $58 \mathrm{~m}$ was estimated with a maximum of $192 \mathrm{~m}$. Our results are also consistent with estimates of a quantitative risk assessment of gene flow from transgenic eucalypts into stands carried out by mathematical modeling. Despite recognizing the uncertainty of the assumption on pollen dispersal, that study concluded that an isolation distance in excess of $100 \mathrm{~m}$ would be needed to limit gene introgression, although full containment would probably require larger distances (Linacre and Ades, 2004).

Pollen flow and dispersal distance in animal pollinated eucalypts is peculiar in that it depends upon several biotic and abiotic factors such as distance among individuals, flowering phenology, pollinator behavior and climatic conditions that affect both flowering phenology and the behavior of pollinator populations. Mating among eucalypts trees are strongly influenced by flowering habits, which are an interaction of genotype and environmental conditions (Law et al., 2000). The behavior of the pollinators partially determines the distance over which pollen can be dispersed (Dick et al., 2008) and pollinators have the potential for long-distance dispersal, especially when pollen resources are scarce and pollen dispersal may therefore occur among trees located over kilometers (Ghazoul, 2005). Still, pollen harvesting by bees is influenced by food acquisition efficiency and quality of pollen that determines the foraging decision (Abrol, 2006). In Brazil, Apis mellifera bees collect pollen of different plants in one visit and were found to promote pollination up to $100 \mathrm{~m}$, decreasing gradually up to distance of $300 \mathrm{~m}$ (Pacheco et al., 1986). Our results taken together with previous studies on pollen flow rate and dispersal distances in eucalypts converge to the fact that pollination will take place by and large at relatively short distances of less than $200 \mathrm{~m}$ consistent with the expected range of flight of pollinator bees. Nevertheless the exponential distribution observed in our study, also indicate that low levels of pollination success are to be expected over longer distances.

It is important to note that our results were drawn from a specific set of three elite hybrid clones and only one of them acting as donor in a single flowering season in a particular environment. Additionally, heterogeneity of experimental designs, sampling schemes, pollination syndromes and bee movement will likely result in differences in pollination patterns from the ones reported herein. It would therefore be imprudent to propose these results to be generally applicable to any clonal stand situation. Rather our results are intended to serve as additional data to help toward an improved understanding of eucalypt pollen dispersal patterns and reproductive success in an exotic environment. Furthermore, we do not have specific data on possible differential genetic compatibility between the PD clone and the two PS clones which could have impacted the overall pollination success of PD, although barriers to genetic compatibility are rarely seen within and between E. grandis, E. urophylla and their hybrids as they belong to the same section (Griffin et al., 1988; Potts and Dungey, 2004). Moreover, given that an overall low level of pollination success was observed for PD with both PS clones, it would be impossible to assess from our experiment if any such differences existed, simply because we did not have enough offspring derived from each one of the two potential crosses. Large numbers of controlled crosses between PD and the two PS clones followed by actual seedling production would be necessary to assess this issue adequately.

We also acknowledge the fact that our estimates of pollination dispersal and success were derived from a deliberately fragmented landscape, so as to provide an experimental setting where distance of pollen flow would likely be extended. Besides the fact that in continuous clonal stands bee access to flowers would be considerably easier, preventing them to have to fly to longer distances, reasoning for this design came also from previous studies that looked at the comparative patterns of pollen dispersal in continuous versus fragmented stands of native Eucalyptus populations. Pollen dispersal in continuous stands of Eucalyptus globulus was shown to occur over considerably shorter distances when compared to the dispersal distances observed across forest fragments, with a greater proportion of paternal trees contributing to the offspring derived from the fragmented stands (Mimura et al., 2009). Similarly, in remnant populations of Eucalyptus wandoo a pollen immigration rate of $65 \%$ was reported coming from populations located at distances of atleast $1 \mathrm{~km}$ (Byrne et al., 2008). Remnant populations of Eucalyptus loxophleba were found to be connected to pollen sources up to $1.94 \mathrm{~km}$ away, indicating that fragmentation may not be associated with decreased gene dispersal, and that distances required to buffer endemic trees in fragmented landscapes in Australia are likely to be large (Sampson and Byrne, 2008). While we recognize that our results in exotic conditions might not be directly comparable to pollen dispersal studies in native habitats, and although we do not have data on the pattern of pollen flow across continuous clonal stands, we speculate that the pollen dispersal estimates we provide could be taken as upper bound estimates in the distances considered and therefore be particularly useful for gene containment modeling studies.

Gene containment from prospective genetically modified (GM) forest trees plantations has been a matter of concern (Brunner et al., 2007). Given the economic importance of eucalypts, and the fact that they are frequently grown as clones in exotic environments, they have been considered strong candidates for the use of transgenic technologies. Still, no GM eucalypt has been approved yet for commercial deployment in Brazil or anywhere in the world (Ledford, 2014), and forest certification agencies still prohibit the commercial deployment of GM trees (Brunner et al., 2007). Since flowering is not necessary in a eucalypt clonal forest for wood production, the use of sterility technologies has been used as a way to prevent transgene dispersal in GM trials in the US (Hinchee et al., 2011). Our results indicate however, that pollination success in clonal eucalypts will still be considerable up to $550 \mathrm{~m}$ and equivalent rates cannot be ruled out at increasing distances. Clearly, transgene escape by pollen flow is inevitable if transgenic eucalypts will eventually be deployed. There is a long way, however, between the generation of an offspring bearing a transgene derived from a pollination event and its effective establishment as a tree an issue that has been studied by modeling approaches where the rate of gene flow is just one of the parameters considered (DiFazio et al., 2012). Moreover, eucalypts seedling establishment in natural conditions in our surveyed environment in Brazil was found to be unlikely, as all eucalypts seedlings were outcompeted by native tree species following 270 days from seed 
sowing (da Silva et al., 2011). Concerns have been raised, however, on the potential economic impacts and food safety perception of the presence, even at very low levels, of transgenic pollen in organic honey produced from eucalypt flowers in Brazil, an issue that has required safety analysis of honey in a recent biosafety assessment of what could be the first commercially released GM eucalypt (Ledford, 2014).

\section{Conclusion}

We have shown that pollen-mediated realized gene flow in fragmented clonal eucalypt stands in an exotic environment suggests a pattern of isolation by distance. Dispersal is concentrated at short distances of less than $200 \mathrm{~m}$ from the source, with low (1-3\%) pollination success expected at higher distances, although pollen spread is still detected up to $550 \mathrm{~m}$, and equivalent levels cannot be ruled out at even increasing distances. Eucalypt pollen flow studies in exotic settings are still scarce and are likely to become progressively more important under the perspective of transgenic tree deployment under forest certification rules. Notwithstanding the intrinsic specificities of these kinds of studies in terms of genotypes sampled and experimental designs adopted, it is important to collect an increasing amount of data by sampling the multiple interactions between genetic, spatial and ecological factors that make predictions of pollen dispersal in any particular landscape a challenging endeavor.

\section{Acknowledgments}

We acknowledge the support provided for this study by Arborgen Ltda.; ArcelorMittal BioEnergia Ltda; Duratex S.A.; Fibria Celulose S/A; International Paper do Brasil Ltda.; Stora Enso Florestal RS Ltda; e Suzano Papel e Celulose S.A. DG had a CNPq research productivity fellowship from CNPq. We are also grateful to the two anonymous reviewers for their constructing comments and for pointing out issues that needed better clarification and focusing throughout the manuscript.

\section{References}

Abrol, D.P., 2006. Foraging behaviour of bees as influenced by quality and quantity of rewards from flowers. J. Asia-Pacific Entomol. 9, 145-148.

Barbour, R.C., Potts, B.M., Vaillancourt, R.E., 2005. Pollen dispersal from exotic eucalypt plantations. Conserv. Genet. 6 (2), 253-257.

Barbour, R.C. et al., 2010. The potential for gene flow from exotic eucalypt plantations into Australia's rare native eucalypts. Forest Ecol. Manage. 260 (12), 2079-2087.

Booth, T.H., 2012. Eucalypts and their potential for invasiveness particularly in frost-prone regions. Int. J. Forestry Res., 7. http://dx.doi.org/10.1155/2012/ 837165 (Article ID 837165).

Brunner, A.M. et al., 2007. Genetic containment of forest plantations. Tree Genet. Genomes 3 (2), 75-100.

Burczyk, J., Adams, W.T., Moran, G.F., Griffin, A.R., 2002. Complex patterns of mating revealed in a Eucalyptus regnans seed orchard using allozyme markers and the neighbourhood model. Mol. Ecol. 11 (11), 2379-2391.

Byrne, M., Elliott, C.P., Yates, C.J., Coates, D.J., 2008. Maintenance of high pollen dispersal in Eucalyptus wandoo, a dominant tree of the fragmented agricultural region in Western Australia. Conserv. Genet. 9 (1), 97-105.

Callaham, M.A.J. et al., 2013. Survey to evaluate escape of Eucalyptus spp. seedlings from plantations in Southeastern USA. Int. J. Forestry Res., 10. http://dx.doi.org 10.1155/2013/946374 (Article ID 946374).

Chaix, G. et al., 2003. Gene flow estimation with microsatellites in a Malagasy seed orchard of Eucalyptus grandis. Theor. Appl. Genet. 107 (4), 705-712.

Chaix, G., Vigneron, P., Razafimaharo, V., Hamon, S., 2007. Are phenological observations sufficient to estimate the quality of seed crops from a Eucalyptus grandis open-pollinated seed orchard? Consequences for seed collections. New Forests 33 (1), 41-52.

Chaix, G., Vigneron, P., Razafimaharo, V., Hamon, S., 2010. Improved management of Malagasy Eucalyptus Grandis seed orchards using microsatellites and paternity assignment. J. Trop. Forest Sci. 22 (3), 271-280. da Silva, P.H.M., Poggiani, F., Sebbenn, A.M., Mori, E.S., 2011. Can Eucalyptus invade native forest fragments close to commercial stands? Forest Ecol. Manage. 261 (11), 2075-2080.

Dick, C.W., Hardy, O.J., Jones, F.A., Petit, R.J., 2008. Spatial scales of pollen and seedmediated gene flow in tropical rain forest trees. Trop. Plant Biol. 1, 20-33.

DiFazio, S.P. et al., 2012. Gene flow and simulation of transgene dispersal from hybrid poplar plantations. The New Phytol. 193 (4), 903-915.

Faria, D.A., Mamani, E.M.C., Pappas, M.R., Pappas, G.J., Grattapaglia, D., 2010. A selected set of EST-derived microsatellites, polymorphic and transferable across 6 Species of Eucalyptus. J. Hered. 101 (4), 512-520.

Gaiotto, F.A., Bramucci, M., Grattapaglia, D., 1997. Estimation of outcrossing rate in a breeding population of Eucalyptus urophylla with dominant RAPD and AFLP markers. Theor. Appl. Genet. 95 (5-6), 842-849.

Ghazoul, J., 2005. Pollen and seed dispersal among dispersed plants. Biol. Rev. 80 (3), 413-443.

Goudet, J., 1995. FSTAT (Version 1.2): a computer program to calculate F-statistics. J. Hered. 86 (6), 485-486.

Grattapaglia, D., Ribeiro, V.J., Rezende, G.D.S.P., 2004. Retrospective selection of elite parent trees using paternity testing with microsatellite markers: an alternative short term breeding tactic for Eucalyptus. Theor. Appl. Genet. 109 (1), 192-199.

Grattapaglia, D., Sederoff, R., 1994. Genetic linkage maps of Eucalyptus grandis and Eucalyptus urophylla using a pseudo-testcross: mapping strategy and RAPD markers. Genetics 137, 1121-1137.

Griffin, A.R., Burgess, I.P., Wolf, L., 1988. Patterns of natural and manipulated hybridisation in the genus Eucalyptus L'Herit. - a review. Aust. J. Bot. 36, 41-66.

Grosser, C., Potts, B.M., Vaillancourt, R.E., 2010. Microsatellite based paternity analysis in a clonal Eucalyptus nitens seed orchard. Silvae Genet. 59 (2-3), 57-62.

Hardner, C.M., Potts, B.M., 1995. Inbreeding depression and changes in variation after selfing Eucalyptus globulus subsp. globulus. Silvae Genet. 44, 46-54.

Hardy, O.J., Vekemans, X., 2002. SPAGEDi: a versatile computer program to analyse spatial genetic structure at the individual or population levels. Mol. Ecol. Notes 2 (4), 618-620.

Hinchee, M. et al., 2011. Biotech eucalyptus can sustainably address society's need for wood: the example of freeze tolerant eucalyptus in the Southeastern U.S. BMC Proc. 5 (Suppl 7), I24.

Hingston, A.B., Gartrell, B.D., Pinchbeck, G., 2004. How specialized is the plantpollinator association between Eucalyptus globulus ssp globulus and the swift parrot Lathamus discolor? Austral. Ecol. 29 (6), 624-630.

Jones, M.E., Shepherd, M., Henry, R., Delves, A., 2008. Pollen flow in Eucalyptus grandis determined by paternity analysis using microsatellite markers. Tree Genet. Genomes 4 (1), 37-47.

Kalinowski, S.T., Taper, M.L., Marshall, T.C., 2007. Revising how the computer program CERVUS accommodates genotyping error increases success in paternity assignment. Mol. Ecol. 16 (5), 1099-1106.

Larcombe, M.J., Silva, J.S., Vaillancourt, R.E., Potts, B.M., 2013. Assessing the invasive potential of Eucalyptus globulus in Australia: quantification of wildling establishment from plantations. Biol. Invas. 15 (12), 2763-2781.

Law, B., Mackowski, C., Schoer, L., Tweedie, T., 2000. Flowering phenology of myrtaceous trees and their relation to climatic, environmental and disturbance variables in northern New South Wales. Austral. Ecol. 25 (2), 160-178.

Ledford, H., 2014. Brazil considers transgenic trees. Nature 512 (7515), 357.

Leite, J.M.D. et al., 2000. Determination of oligosaccharides in Brazilian honeys of different botanical origin. Food Chem. 70 (1), 93-98.

Linacre, N.A., Ades, P.K., 2004. Estimating isolation distances for genetically modified trees in plantation forestry. Ecol. Model. 179 (3), 247-257.

Loiselle, B.A., Sork, V.L., Nason, J., Graham, C., 1995. Spatial genetic-structure of a tropical understory shrub, Psychotria officinalis (Rubiaceae). Am. J. Bot. 82 (11), 1420-1425.

Marshall, T.C., Slate, J., Kruuk, L.E.B., Pemberton, J.M., 1998. Statistical confidence for likelihood-based paternity inference in natural populations. Mol. Ecol. 7 (5), 639-655.

Mimura, M., Barbour, R.C., Potts, B.M., Vaillancourt, R.E., Watanabe, K.N., 2009 Comparison of contemporary mating patterns in continuous and fragmented Eucalyptus globulus native forests. Mol. Ecol. 18 (20), 4180-4192.

Pacheco, I.A., Kageyama, P.Y., Wiendl, E.M., Berti Filho, E., 1986. Estudo da dispersão de pólen de Eucalyptus saligna Smith por abelhas Apis mellifera L. utilizando-se o radio fósforo 32P. Scientia Forestalis 34, 47-52.

Potts, B.M., Dungey, H.S., 2004. Interspecific hybridization of eucalyptus: key issues for breeders and geneticists. New Forests 27 (2), 115-138.

Rezende, G.D.S.P., Resende, M.D.V., Assis, T.F., 2014. Eucalyptus breeding for clonal forestry. In: Fenning, T. (Ed.), Challenges and Opportunities for the World's Forests in the 21st Century. Springer Science+Business Media, Dordrecht, pp. 393-424.

Sampson, J.F., Byrne, M., 2008. Outcrossing between an agroforestry plantation and remnant native populations of Eucalyptus loxophleba. Mol. Ecol. 17 (11), 27692781.

Southerton, S.G., Birt, P., Porter, J., Ford, H.A., 2004. Review of gene movement by bats and birds and its potential significance for eucalypt plantation forestry Aust. Forestry 67 (1), 44-53. 